\title{
Leukocytoclastic vasculitis as a rare dermatologic manifestation of Crohn's disease mimicking cellulitis: a case report
}

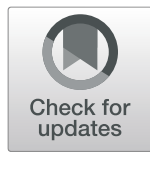

Meredith Buck', Igor Dumic ${ }^{2,3^{*}}$ D, Wendy McDermott ${ }^{2,3}$, Charles Nordstrom ${ }^{2,3}$, Samarth Dawan ${ }^{4}$, Andrew Virata ${ }^{2,5}$, Scott Martin 2,5 , Ann Hudson ${ }^{2,3}$, Tamara Milovanovic ${ }^{6}$ and Terri Nordin ${ }^{1,2,7}$

\begin{abstract}
Background: Leukocytoclastic vasculitis (LCV) is an immune-complex mediated vasculitis characterized by neutrophilic inflammation and nuclear debris in post capillary venules. LCV is a rare dermatologic manifestation of Crohn's disease (CD) and may occur with the onset of the disease or any time after the diagnosis including the period of exacerbation.

Case presentation: We present a 70 year old woman with history of psoriasis and treatment refractory CD requiring monoclonal antibody therapy with ustekinumab. One month prior to the current admission, she developed abdominal pain, worsening diarrhea and was diagnosed with CD exacerbation for which she was given ustekinumab. While her abdominal symptoms mildly improved with ustekinumab, she developed new bilateral lower extremity rash initially treated with levofloxacin for presumed cellulitis. The rash consisted of mild erythematous, non-scaling patches with scattered non-palpable petechiae on the lower extremities with subsequent involvement of abdomen, lower back and buttocks. Abdominal exam showed diffuse tenderness without mass, guarding or rebound while reminder of physical exam was unremarkable. Following the failure of antimicrobial therapy, she was diagnosed with LCV by skin biopsy. Complete work up was negative for infectious, malignant and inflammatory etiologies of LCV. Patient improved with increased dose of budesonide and subsequently continued to tolerate ustekinumab without recurrence of LCV.

Discussion and conclusion: $L C V$ is a rare form of vasculitis and one of the rarest dermatologic manifestations of $C D$, appearing at any stage of the disease. LCV has been associated with autoimmune diseases, infections, specific drugs (levofloxacin, ustekinumab), and malignancy. Clinical presentation of LCV is variable and frequently mistaken for cellulitis. LCV should be considered in differential diagnosis of bilateral lower extremity rash in patients with CD after infectious, malignant and auto-immune/inflammatory etiologies are excluded. Unlike erythema nodosum (EN) and pyoderma gangrenosum (PG), LCV requires biopsy for diagnosis. Most patients respond well to steroids without scarring.
\end{abstract}

Keywords: Leukocytoclastic vasculitis, Crohn's disease, Dermatologic manifestation, Cellulitis, Inflammatory bowel disease, Ustekinumab, Levofloxacin, Case report

\footnotetext{
* Correspondence: Dumic.lgor@mayo.edu

${ }^{2}$ Mayo Clinic Alix College of Medicine and Science, Rochester, MN, USA

${ }^{3}$ Division of Hospital Medicine, Mayo Clinic Health System, Eau Claire, WI, USA

Full list of author information is available at the end of the article
}

C C The Author(s). 2020 Open Access This article is licensed under a Creative Commons Attribution 4.0 International License, which permits use, sharing, adaptation, distribution and reproduction in any medium or format, as long as you give appropriate credit to the original author(s) and the source, provide a link to the Creative Commons licence, and indicate if changes were made. The images or other third party material in this article are included in the article's Creative Commons licence, unless indicated otherwise in a credit line to the material. If material is not included in the article's Creative Commons licence and your intended use is not permitted by statutory regulation or exceeds the permitted use, you will need to obtain permission directly from the copyright holder. To view a copy of this licence, visit http://creativecommons.org/licenses/by/4.0/. The Creative Commons Public Domain Dedication waiver (http://creativecommons.org/publicdomain/zero/1.0/) applies to the data made available in this article, unless otherwise stated in a credit line to the data. 


\section{Background}

Inflammatory bowel disease (IBD) encompasses the two major entities of ulcerative colitis (UC) and Crohn's disease (CD). Both diseases are chronic inflammatory disorders of poorly understood etiology, thought to occur in genetically predisposed individuals as result of an abnormal immunologic response to intestinal microbiome. UC lesions involve the mucosal and submucosal layers and are limited to the colon. CD lesions are transmural and typically involve the terminal ileum and colon, but may occur anywhere in the gastrointestinal tract from the mouth to perianal tissues with skipped areas of involvement [1]. Up to $40 \%$ of patients with IBD experience extra-intestinal manifestations (EIM), which occur more commonly in CD compared to UC. The most common EIM are musculoskeletal (peripheral arthritis), ocular (uveitis) and dermatologic [2]. The most common dermatologic manifestations of IBD are erythema nodosum (EN), pyoderma gangrenosum (PG) and aphthous stomatitis [3]. Less commonly seen dermatologic manifestations include neutrophilic dermatoses (Sweet's syndrome), cutaneous vasculitis, epidermolysis bullosa acquisita, and metastatic CD [2, 3].

Leukocytoclastic vasculitis (LCV) is the rarest dermatologic manifestation of CD. Vasculitis is defined as a leukocyte-mediated inflammation of vessel walls, and may cause varying degrees of vessel destruction leading to hemorrhagic or ischemic events [4]. Vasculitides are classified by the size of blood vessels involved and by the dominant immune cells involved in the inflammation. LCV is an immune-mediated, small vessel vasculitis where inflammation is dominated by neutrophils, with fibrinoid necrosis and nuclear debris deposition (karyorrhexis) leading to post capillary venules damage [4]. The etiology of LCV is an abnormal immune response that may be precipitated by infections (e.g. viral hepatitis), medications (e.g. ustekinumab, levofloxacin), various malignancies, inflammatory/autoimmune diseases, or idiopathic stimuli $[4,5]$.

Here, we report a case of a patient with refractory CD whose clinical course was complicated by LCV, and discuss its challenging diagnosis in the context of previously reported cases.

\section{Case presentation}

A 74-year-old woman, with a history of treatmentrefractory Crohn's disease on budesonide therapy $(6 \mathrm{mg}$ daily), psoriasis, and pernicious anemia developed abdominal pain, cramping, and non-bloody diarrhea 8 weeks prior to her current hospital admission. Colonoscopy was performed at onset of these flare of symptoms and demonstrated edema, erythema, and erosions at the ileocolic anastomosis (Fig. 1) with biopsies revealing severe active ileocolitis (Fig. 2). Standard dose of ustekinumab was added to her chronic budesonide regimen with moderate improvement in her symptoms. Approximately 6 weeks after ustekinumab was started and 2 weeks prior to her current admission, she was evaluated in urgent care with complaints of low-grade fever and a tender, non-pruritic bilateral lower extremity rash. At that time she began treatment with oral levofloxacin for presumed cellulitis. Her rash subsequently progressed, spreading to the abdomen and upper extremities. Her subjective fevers persisted, and she developed headache, fatigue, arthralgias, and generalized weakness along with worsening of abdominal pain and diarrhea. Given worsening of her symptoms despite antibiotic therapy, she presented to the emergency department for further evaluation and was admitted for presumed ineffective outpatient treatment of cellulitis and intravenous vancomycin therapy.

She was a retired factory worker from Wisconsin, USA who had been diagnosed with Crohn's ileitis 30 years prior (A1, L3, B1) and maintained on budesonide. Prior therapies ineffective for her $\mathrm{CD}$ included mesalamine, prednisone, and adalimumab. Methotrexate trial was not tolerated due to allergic reaction (hives), and both infliximab and vedolizumab led to worsening of her psoriasis. Following the latest CD flare up standard dose of ustekinumab had been added to budesonide with the plan to continue the regimen with 8 week dosing intervals.

The patient was a former smoker who did not drink alcohol or use illicit drugs. Her medications included ustekinumab, budesonide, vitamin B12 injections and a multivitamin. Her psoriasis had been quiescent, and had required no recent treatment.

On physical exam she appeared well-developed in mild distress due headache, abdominal pain, and painful rash. Patient was febrile to $38.2^{\circ} \mathrm{C}$; other vital signs were normal. Oral mucosa was moist and without ulcerations. Lungs were clear to auscultation bilaterally and heart sounds were regular, and without murmur. Abdominal exam revealed tenderness to deep palpation in the right lower quadrant without peritoneal signs. Rectal exam was negative for perianal fistulas. Neurologic exam was normal. Skin exam was remarkable for a tender, petechial rash involving her abdomen and extremities (Fig. 3).

A complete blood cell count demonstrated hemoglobin of $13.0 \mathrm{~g} / \mathrm{dL}$, white blood cell count of $5.7 \mathrm{x}$ $\times 10^{9} / \mathrm{L}$, and platelet count of $133 \times 10^{9} / \mathrm{L}$. A comprehensive metabolic panel demonstrated normal electrolytes, renal and liver function. Tick-borne panel including testing for Lyme disease, Anaplasma spp, Ehrlichia spp and Babesia microti was negative as well as blood cultures. Inflammatory markers were elevated with sedimentation rate (ESR) $42 \mathrm{~mm} / \mathrm{h}$, and C-reactive protein (CRP) $15.2 \mathrm{mg} / \mathrm{L}$. Rheumatoid factor, cryoglobulins, and anti-nuclear antibody (ANA) were negative. 


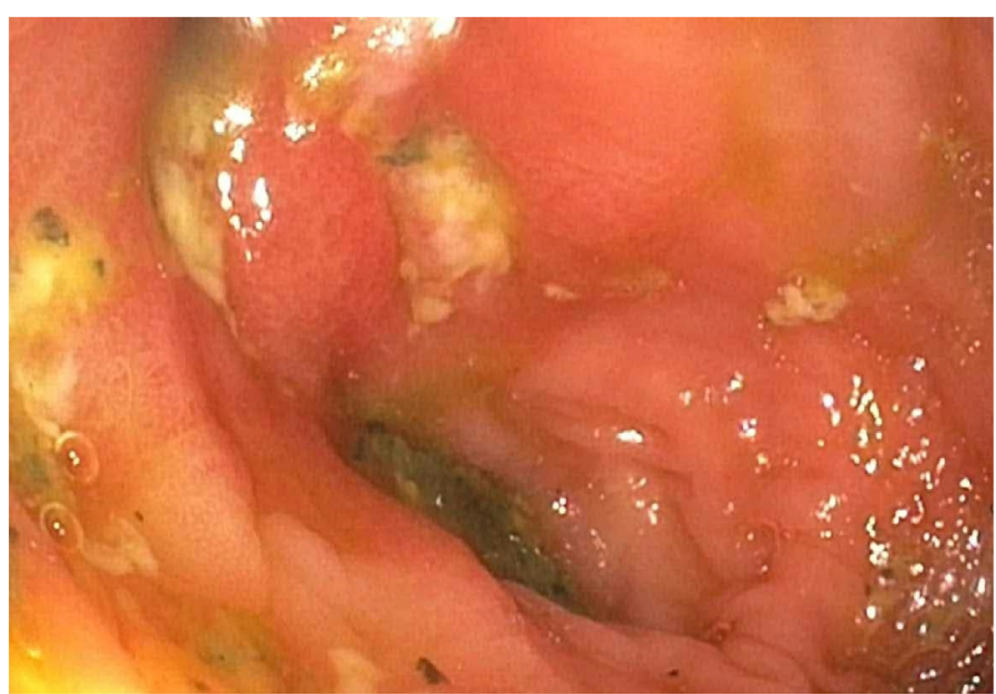

Fig. 1 Findings from colonoscopy demonstrating hyperemic mucosa with superficial ulcerations

Serum protein electrophoresis (SPEP) was negative for monoclonal protein spikes. Complement $\mathrm{C} 3$ and $\mathrm{C} 4$ levels were within normal range. Testing for viral hepatitis including Hepatitis A, B, and C were negative for both acute and chronic infection, and showed immunity against Hepatitis B virus. Cerebrospinal fluid (CSF) demonstrated a nucleated cell count of 0 with normal glucose and protein. A non-contrast head CT was negative for intracranial lesions. Recent mammogram and cervical cancer screening were normal.

In the absence of leukocytosis and coupled with the symmetric distribution of the rash, cellulitis seemed unlikely, leading to discontinuation of antibiotics. Evaluation of rash with skin biopsy demonstrated findings consistent with leukocytoclastic vasculitis, including: 1) neutrophilic infiltration of the blood vessels with necrosis and perivascular fibrinoid deposition, 2) disruption of some small caliber blood vessels walls with hints of fibrin deposition, 3) bits of nuclear dust in and around blood vessel walls, and 4) extravasated erythrocytes (Fig. 4). A Periodic acidSchiff stain (with appropriate positive control) did not demonstrate spore or hyphal form. Bacterial cultures of skin and blood remained negative.

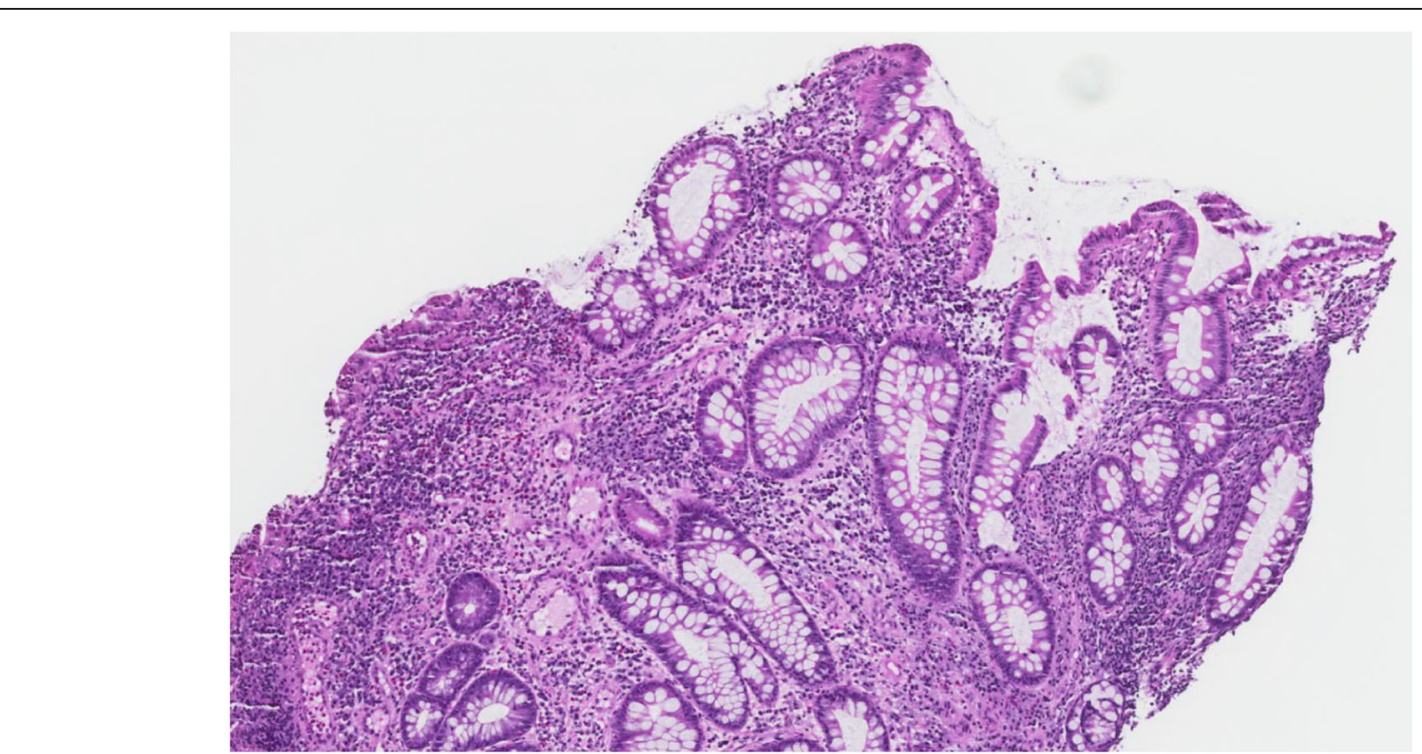

Fig. 2 Biopsy of terminal ileum showing active chronic inflammation with ulceration consistent with Crohn's disease (H\&E stain, 40 $x$ magnifications) 


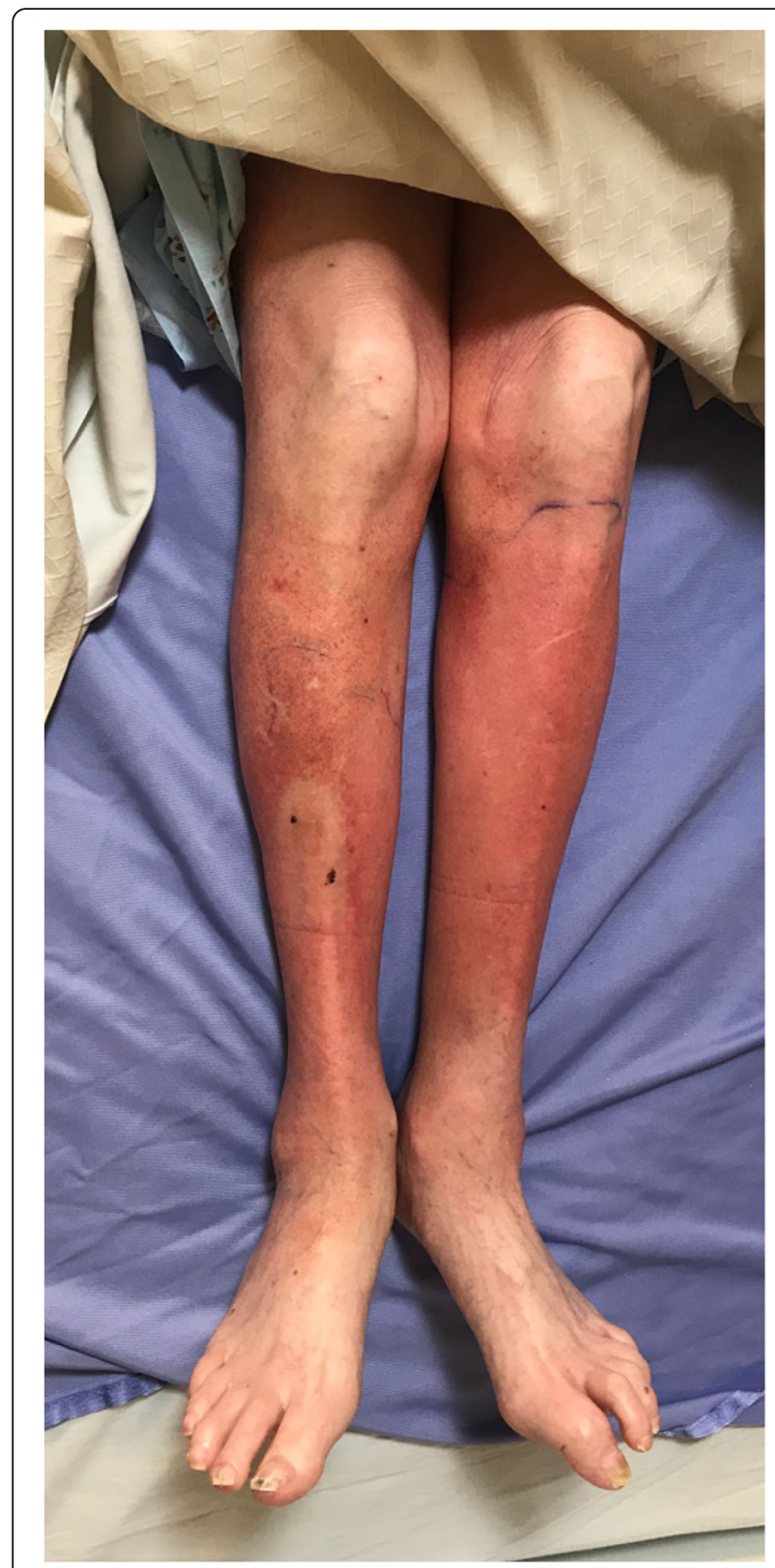

Fig. 3 Tender macular erythematous rash involving the extensor surface of the lower limbs

High dose intravenous steroids were recommended as treatment of choice, but patient declined. Budesonide dose was subsequently increased from $6 \mathrm{mg}$ to $9 \mathrm{mg}$ daily, and within $48 \mathrm{~h}$ her rash began to subside, and patient noted improvement in abdominal pain and constitutional symptoms. Prior to discharge, she received another dose of ustekinumab without exacerbation of her rash, and with continued improvement in her gastrointestinal and constitutional symptoms. Eight months following her episode of CD flare associated with LCV she continued to do well on ustekinumab and budesonide has been gradually tapered off.

\section{Discussion and conclusion}

Based on pathogenesis, IBD-associated skin disorders can be classified into the following groups: cutaneous granulomatous lesions with the same histological characteristics as IBD; reactive cutaneous manifestation due to shared antigens between gut microbes and the skin via antigen mimicry (such as with EN and PG); and dermatoses associated with IBD or its complications $[3,6]$. Cutaneous manifestations of IBD are more common in females and particularly in those diagnosed at younger age and with family history of IBD [7-9].

Current postulates suggest that the rarest form of IBD-related skin disorders, LCV, is a reactive cutaneous manifestation [2, 7]. In spite of limited understanding of the pathogenesis of LCV in patients with IBD, several theories exist. One of the most plausible theories, the "theory of antigen mimicry," postulates that certain epitopes of gut and skin flora are shared, very similar, or identical. Bacteria "leaks "through inflamed intestinal mucosa damaged by IBD and trigger an adaptive immune response. In some genetically predisposed individuals, the immune system is not able to discriminate between the epitopes of gut flora and those of the skin. Antigen-antibody immune complexes deposit in the skin, or in the case of LCV, within the small blood vessels of the dermis. This, in turn, causes inflammation and blood vessel destruction, erythrocyte extravasation, and manifestation of purpura. The proposed genetic predisposition may explain why some people develop EIM while others don't. Data demonstrating presence of EIM in up to $84 \%$ of sibling pairs supports the genetic predisposition theory [9].

LCV most commonly presents as palpable purpura involving the lower extremities and may be pruritic or painful $[7,10]$. It can, however, present in various forms such as erythema only, a petechial rash, a maculopapular rash, nodules, and various locations such as legs, abdomen or arms (Table 1). Similarly to other cutaneous IBD manifestations, LCV may occur independent of the disease activity of $\mathrm{CD}$, yet in contrast to other skin manifestations of IBD manifestations, there are no reported cases of $\mathrm{LCV}$ preceding the $\mathrm{CD}$ diagnosis as it typically occurs either at the onset of CD or following its diagnosis. While PG can leave significant aesthetic sequela, LCV usually (but not always) resolves without scarring [10-21].

A PubMed database literature search for articles published in the English language including the key words "leukocytoclastic vasculitis" and "Crohn's disease" yielded the 14 cases summarized in Table 1 [10-21].

In all identified cases represented in Table 1 and the case discussed herein, the rash affected the extensor surfaces of the bilateral lower extremities. In $35 \%$ of these 14 cases, the rash spread proximally to involve the 


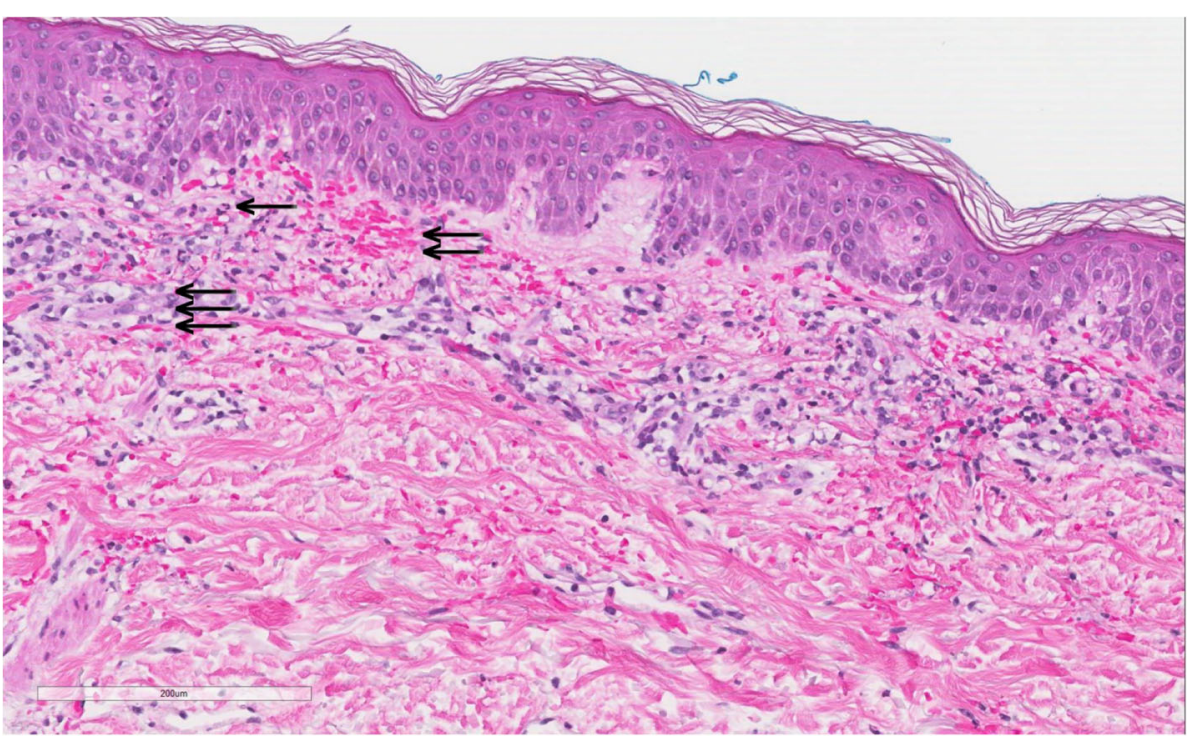

Fig. 4 Skin biopsy (H\&E stain,10x magnification) demonstrates inflammation with leukocytoclastic debris - karyorrhexis- (arrow), extravasated red blood cells (double arrow) and fibrinoid vascular degeneration (triple arrow) consistent with leukocytoclastic vasculitis

Table 1 Summarize previously published cases of LCV associated with CD

\begin{tabular}{|c|c|c|c|c|c|c|c|c|c|c|}
\hline $\begin{array}{l}\text { Case/ } \\
\text { Reference }\end{array}$ & $\begin{array}{l}\text { Year of } \\
\text { Publication }\end{array}$ & First Author & $\begin{array}{l}\text { Patient } \\
\text { age }\end{array}$ & $\begin{array}{l}\text { Patient } \\
\text { Gender }\end{array}$ & Etiology & $\begin{array}{l}\text { Location of } \\
C D\end{array}$ & Activity of CD & $\begin{array}{l}\text { Location } \\
\text { of rash }\end{array}$ & Therapy & $\begin{array}{l}\text { Recurrence } \\
\mathrm{Y} / \mathrm{N}\end{array}$ \\
\hline $1[10]$ & 1996 & Zlatanic & 39 & M & $C D$ & $\begin{array}{l}\text { Transverse } \\
\text { and sigmoid } \\
\text { colon }\end{array}$ & Active & Legs & IV hydrocortisone & $\mathrm{N}$ \\
\hline $2[11]$ & 2002 & Mcllwain & 24 & $\mathrm{~F}$ & Infliximab & $\begin{array}{l}\text { Terminal } \\
\text { ileum }\end{array}$ & Active & $\begin{array}{l}\text { Legs and } \\
\text { arms }\end{array}$ & Methylprednisolone & N \\
\hline $3[12]$ & 2008 & Tsiamoulous & 80 & M & $C D$ & Colon & $\begin{array}{l}\text { Initial } \\
\text { manifestation } \\
\text { (active) }\end{array}$ & Legs & IV Prednisolone & $\mathrm{N}$ \\
\hline 4 [113] & 2010 & Limdi & 52 & M & $C D$ & Ileum & Quiescent & Legs & IV steroids & $\mathrm{N}$ \\
\hline $5[14]$ & 2013 & Karatoprak & 28 & M & $C D$ & Jejunum & $\begin{array}{l}\text { Initial } \\
\text { manifestation } \\
\text { (active) }\end{array}$ & Legs & Prednisone & N \\
\hline $6[15]$ & 2016 & Namakura & 35 & M & Infliximab & NR & Quiescent & Legs & $\begin{array}{l}\text { Spontaneous } \\
\text { resolution }\end{array}$ & N \\
\hline $7[16]$ & 2017 & Bernardes & 29 & $\mathrm{~F}$ & Adalimumab & Colon & NR & $\begin{array}{l}\text { Legs and } \\
\text { abdomen }\end{array}$ & $\begin{array}{l}\text { Discontinuation of } \\
\text { Adalimumab }\end{array}$ & Y \\
\hline $8[16]$ & 2017 & Bernardes & 60 & M & Adalimumab & Ileocolon & NR & Legs & $\begin{array}{l}\text { Discontinuation of } \\
\text { Adalimumab }\end{array}$ & $\mathrm{N}$ \\
\hline $9[16]$ & 2017 & Bernardes & 44 & $\mathrm{~F}$ & Adalimumab & Colon & NR & Legs & $\begin{array}{l}\text { Discontinuation of } \\
\text { Adalimumab }\end{array}$ & Y \\
\hline 10 [17] & 2017 & Goncalves & 51 & M & $C D$ & $\begin{array}{l}\text { Sigmoid and } \\
\text { rectum }\end{array}$ & $\begin{array}{l}\text { Initial } \\
\text { manifestation } \\
\text { (active) }\end{array}$ & $\begin{array}{l}\text { Legs, } \\
\text { thighs, } \\
\text { arms }\end{array}$ & Prednisone & Y \\
\hline 11 [18] & 2017 & Woody & 28 & $\mathrm{~F}$ & Certolizumab & NR & NR & $\begin{array}{l}\text { Legs, } \\
\text { feet, } \\
\text { palms }\end{array}$ & $\begin{array}{l}\text { Prednisone, } \\
\text { Dapsone }\end{array}$ & $\mathrm{N}$ \\
\hline 12 [19] & 2017 & Cury & 28 & $\mathrm{~F}$ & Adalimumab & NR & Quiescent & Legs & Colchicine & $\mathrm{N}$ \\
\hline $13[20]$ & 2018 & Fonseca & 38 & $\mathrm{~F}$ & Infliximab & Ileum & Quiescent & Legs & Prednisone & $N$ \\
\hline 14 [21] & 2019 & $\begin{array}{l}\text { Costa- } \\
\text { Moreira }\end{array}$ & 28 & $\mathrm{~F}$ & Ustekinumab & Perianal & Quiescent & $\begin{array}{l}\text { Legs and } \\
\text { abdomen }\end{array}$ & Prednisone & Y \\
\hline
\end{tabular}


abdomen and upper extremities. The patient in this case was initially misdiagnosed with cellulitis similar to the case reported by Limdi and Doran [13]. Both LCV and cellulitis display a similar constellation of constitutional signs and symptoms, fever, and rash. One important difference in these conditions to emphasize is that cellulitis rarely, if ever, presents in a bilateral distribution while vasculitis typically does [22]. Similar to this case, the majority of cases presented with a purpuric or petechial rash, which histologically corresponds to blood extravasation from small blood vessels due to vessel necrosis. While the clinical picture in the appropriate setting is sufficient for the diagnosis of PG or EN, skin biopsy remains the gold standard for LCV diagnosis and rules out infection or other causes of vasculitis.

Our patient developed LCV during an exacerbation of her CD. As shown in Table 1, a minority of cases of LCV were attributed directly to CD, while most cases $(9$ of $14,62 \%$ ) were attributed to the biological agents used to treat $\mathrm{CD}$. Of 14 patients that we summarized in this review, 10 reported disease activity (e.g. quiescent vs. active). In five patients LCV developed during active CD (i.e. exacerbation) while the remaining $50 \%$ LCV occurred during clinically silent intestinal disease. While EN has been associated with disease activity, PG and LCV might or might not parallel intestinal disease activity $[8,9,23]$. Ileocolonic location of $\mathrm{CD}$ (as seen in our patient) has been associated with higher probability of development of EN or PG according to some authors [9, 24], however recent study of a Swiss IBD cohort did not demonstrate difference in disease location in patients who developed skin manifestation compared to those who did not [8]. In $40 \%$ of patients summarized in this review, approximately $40 \%$ (6 out of 14) had CD localized to large bowel.

Before attributing LCV as an EIM of IBD, it is important to exclude other etiologies that frequently accompany the disease, namely: medications, malignancy, connective tissue disorders, and infection. Given that steroids are the cornerstone of treatment for LCV, it is imperative that alternative causes of rash be thoroughly evaluated to avoid exacerbation of infection with steroid therapy.

Documented cases implicate both levofloxacin and ustekinumab in causing LCV $[21,25]$. Levofloxacin as the cause of LCV in our case seemed unlikely given the presence of lesions prior to its administration. Ustekinumab was recently reported as a cause of vasculitis [21], adding it to the list of monoclonal antibodies implicated in $\operatorname{LCV}[11,15,16,19,20]$. We considered ustekinumab as an etiology in this case, yet it seemed less likely when our patient tolerated re-initiation and long-term continuation of this medication without worsening of her LCV. While there is a possibility that the LCV was in fact due to ustekinumab and that higher doses of budesonide lead to clinical resolution, tapering off of budesonide with concurrent re-introduction of ustekinumab did not lead to reappearance of LCV. Thus, we can rule out medication induced LCV. As ustekinumab is a relatively new medication in armamentarium used to treat $\mathrm{CD}$, it remains to be seen at what extent it might influence development of LCV. The only case report to date where LVC developed due to ustekinumab occurred after 3 years of therapy, while intestinal disease was in remission, and re-challenge with ustekinumab resulted in rapid re-appearance of LCV [21].

In our case, the patient's recent and normal ageappropriate screening by mammogram, pap smear, and colonoscopy made malignancy an unlikely cause of LCV. Additionally, the extensive evaluation for other autoimmune disorders, connective tissue disease, and infection were unremarkable.

LCV responds well to steroid therapy and resolves quickly without scarring in most cases reported. Namakura [15] and colleagues reported a case of spontaneous resolution; Bernardes [16] reported 3 cases resolving without steroid therapy after withdrawal of adalimumab, and one case reported steroid-resistant LCV which resolved with colchicine [19]. While the rash subsides within days in the majority of cases, longer time to resolution has been reported [19]. The longest duration of rash reported was 9 months where infliximab was the inciting agent and no treatment or medication changes took place [19].

LCV is rare cutaneous manifestation of CD sometimes initially misdiagnosed as cellulitis. Clinicians should consider it in the differential diagnosis of patients with $\mathrm{CD}$ who present with constitutional symptoms and bilateral lower extremity rash. In approximately $30 \%$ of patients the rash can spread upwards to include abdomen, thorax and upper extremities and in more than $50 \%$ of reported cases it was associated with biologic therapy and not $\mathrm{CD}$ itself. In $50 \%$ of patients LCV occurred during $\mathrm{CD}$ exacerbation and $40 \%$ of patients had disease localized to the colon. Unlike other clinically diagnosable dermatologic manifestation of IBD, LCV requires a skin biopsy for diagnosis. In cases of suspected medicationinduced LCV, appropriate management includes withdrawing the inciting medication. Systemic steroids show effectiveness for hastening recovery.

\section{Abbreviations}

ANA: Anti-nuclear antibody; CD: Crohn's disease; CRP: C-reactive protein; CSF: Cerebrospinal fluid; EN: Erythema nodosum; EIN: Extra-intestinal manifestations; ESR: Sedimentation rate; IBD: Inflammatory bowel disease; LCV: Leukocytoclastic vasculitis; NR: Not reported; PAS: Periodic acid-Schiff stain; PG: Pyoderma gangrenosum; SPEP: Serum protein electrophoresis; UC: Ulcerative colitis 


\section{Acknowledgments}

Not applicable.

\section{Authors' contributions}

$M B, I D$, and TN designed the manuscript; WM, AV, SM, and AH-collected data; WM, TM, ID, TN, SM, and AV- helped with data interpretation; MB, ID, $\mathrm{SD}, \mathrm{CN}, \mathrm{TM}$, and TN- wrote and edited manuscript; All authors have read and approved the final manuscript

\section{Funding}

Not applicable

\section{Availability of data and materials}

All data are included within the manuscript

\section{Ethics approval and consent to participate}

Not applicable

\section{Consent for publication}

Written informed consent was obtained from the patient for publication of this case report including all the images. A copy of the written consent is available for review by the Editor of this journal.

\section{Competing interests}

None of the authors have any competing interest or conflicts of interest to declare

\section{Author details}

'Mayo Clinic Family Medicine Residency - Eau Claire Program, Eau Claire, WI, USA. ${ }^{2}$ Mayo Clinic Alix College of Medicine and Science, Rochester, MN, USA. ${ }^{3}$ Division of Hospital Medicine, Mayo Clinic Health System, Eau Claire, WI, USA. ${ }^{4}$ Icahn School of Medicine at Mount Sinai, New York City, NY, USA. ${ }^{5}$ Department of Pathology, Mayo Clinic Health System, Eau Claire, WI, USA. ${ }^{6}$ Department of Gastroenterology, Clinical Center of Serbia, Belgrade, Serbia. 'Department of Family Medicine, Mayo Clinic Health System, Eau Claire, WI, USA.

Received: 3 November 2019 Accepted: 9 June 2020

Published online: 29 July 2020

\section{References}

1. Ramos, Guilherme Piovezani et al. Mechanisms of Disease: Inflammatory Bowel Diseases Mayo Clinic Proceedings, Volume 94, Issue 1, 155-165.

2. Vavricka SR, Brun L, Ballabeni P, Pittet $V$, et al. Frequency and risk factors for extraintestinal manifestations in the Swiss inflammatory bowel disease cohort. Am J Gastroenterol. 2011:106(1):110-9.

3. Huang BL, Chandra S, Shih DQ. Skin manifestations of inflammatory bowe disease. Front Physiol. 2012:3:13.

4. Jennette JC, Falk RJ, Bacon PA. at all2012 Revised international Chapel Hill consensus conference nomenclature of Vasculitides. Arthritis Rheum. 65:1-11. https://pubmed.ncbi.n/m.nih.gov/23045170/.

5. Carlson JA, Chen KR. Cutaneous vasculitis update: small vessel neutrophilic vasculitis syndromes. Am J Dermatopathol. 2006;28(6):486-506.

6. Hindryckx P, Novak G, Costanzo A, Danese S. Disease-related and druginduced skin manifestations in inflammatory bowel disease. Expert Rev Gastroenterol Hepatol. 2017;11(3):203-14.

7. Su CG, Judge TA, Lichtenstein GR. Extraintestinal manifestations of inflammatory bowel disease. Gastroenterol Clin N Am. 2002;31:307-27.

8. Roth N, Biedermann L, Fournier N, Butter M, Vavricka SR, Navarini AA, et al. Occurrence of skin manifestations in patients of the Swiss inflammatory bowel disease cohort study. PLoS One. 2019;14(1):e0210436.

9. Ampuero J, Rojas-Feria M, Castro-Fernández M, Cano C, Romero-Gómez M Predictive factors for erythema nodosum and pyoderma gangrenosum in inflammatory bowel disease. J Gastroenterol Hepatol. 2014;29(2):291-5.

10. Zlatanic J, Fleisher M, Sasson M, Kim P, Korelitz Bl. Crohn's disease and acute leukocytoclastic vasculitis of skin. Am J Gastroenterol. 1996:91(11):2410-3.

11. Mcllwain L, Carter JD, Bin-Sagheer S, et al. Hypersensitivity vasculitis with leukocytoclastic vasculitis secondary to infliximab. J Clin Gastroenterol. 2003 May-Jun;36(5):411-3.
12. Tsiamoulos Z, Karamanolis G, Polymeros D, Triantafyllou K, Oikonomopoulos T. Leukocytoclastic vasculitis as an onset symptom of Crohn's disease. Case Rep Gastroenterol. 2008;2(3):410-4. https://doi.org/10.1159/000161562.

13. Limdi JK, Doran HM, Crampton JR. Cutaneous vasculitis in Crohn's disease. Crohns Colitis. 2010;4(Issue 3):351-2.

14. Karatoprak C, Arabaci E, Yildiz K, et al. Gastroenterology cases of cutaneous leukocytoclastic vasculitis. Case Rep Med. 2013;2013:264189. https://doi.org/ 10.1155/2013/264189.

15. NumakuraT TT, Nara $M$, et al. Simultaneous development of sarcoidosis and cutaneous vasculitis in a patient with refractory Crohn's disease during infliximab therap. BMC Pulm Med. 2016:16:30.

16. Bernardes C, Carvalho D, Saiote J, et al. Leukocytoclastic vasculitis complicating adalimumab therapy for Crohn's disease: Report of three cases. Gastroenterol Hepatol. 2018;41(7):442-3.

17. Gonçalves MJ, Romão VC, Soares-de-Almeida L, et al. Erythema elevatum diutinum in Crohn's disease-associated Spondyloarthritis - a rare vasculitis, an unusual association. Acta Reumatol Port. 2017:42(4):324-8.

18. Woody M, Warren D, Speck L, Jackson J. Leukocytoclastic vasculitis drug reaction to certolizumab pegol. Proc (Baylor Univ Med Cent). 2017;30(2): 213-4. https://doi.org/10.1080/08998280.2017.11929591.

19. Cury DB, de Souza AW, Vianna GA, et al. Cutaneous Vasculitis in a patient with Crohn's disease treated with Adalimumab. Inflamm Bowel Dis. 2017; 23(1):E1-2.

20. Chebli JMF, de Oliveira Moreira B, da Rocha Ribeiro TC. An unusual cause of skin rash in Crohn's disease. Gastroenterology. 2018;155:618-20.

21. Costa-Moreira P, Lopes S, Santos AL, et al. Leukocytoclastic Vasculitis related to Ustekinumab in a Crohn's disease patient: first case report and literature review. J Crohns Colitis. 2019;2. https://pubmed.ncbi.nlm.nih.gov/31267125/.

22. Emily C. Keller, Kenneth J. Tomecki and M. Chadi Alraies. Distinguishing cellulitis from its mimics. Cleve Clin J Med. 2012;79(8):547-52.

23. Greuter T, Vavricka SR. Extraintestinal manifestations in inflammatory bowel disease - epidemiology, genetics, and pathogenesis. Expert Rev Gastroenterol Hepatol. 2019;13(4):307-17.

24. Tavarela VF. Review article: skin complications associated with inflammatory bowel disease. Aliment Pharmacol Ther. 2004;20(Suppl 4):50-3.

25. Blyth DM, Markelz E, Okulicz JF. Cutaneous leukocytoclastic vasculitis associated with levofloxacin therapy. Infect Dis Rep. 2012:4(1):e11. Published 2012 Jan 30. https://doi.org/10.4081/idr.2012.e11

\section{Publisher's Note}

Springer Nature remains neutral with regard to jurisdictional claims in published maps and institutional affiliations.

Ready to submit your research? Choose BMC and benefit from:

- fast, convenient online submission

- thorough peer review by experienced researchers in your field

- rapid publication on acceptance

- support for research data, including large and complex data types

- gold Open Access which fosters wider collaboration and increased citations

- maximum visibility for your research: over $100 \mathrm{M}$ website views per year

At BMC, research is always in progress.

Learn more biomedcentral.com/submissions 